\title{
Mecanismos de exclusão em duas empresas em processo de reestruturação
}

\section{Lea Carvalho Rodrigues 1 Catia Regina Muniz}

Enfatizamos, neste artigo, a importância da dimensão simbólica no estudo de empresas e organizações, sobretudo no decorrer de processos de reestruturação e tomamos como foco analítico os mecanismos de exclusão observados em duas empresas sobre as quais foram realizados estudos etnográficos, ambos finalizados no ano 2000, durante o período em que essas empresas passavam por significativos processos de mudanças (Rodrigues, 2001; Muniz, 2001). O primeiro caso, refere-se a uma fábrica localizada no interior do estado de São Paulo, com filial em Recife, ligada a um grupo anglo-holandês, que produz produtos pessoais tais como: desodorantes, xampus, sabonetes líquidos, cremes hidratantes e cremes dentais; 0 outro, refere-se a uma empresa do setor financeiro nacional com participação acionária majoritária do governo federal.

${ }^{1}$ Lea Carvalho Rodrigues é doutora em Ciências Sociais pela Unicampe professora da Universidade Federal do Ceará (UFC). E-mail: learodrigues@terra.com.br. Catia Regina Muniz. é doutoranda em Ciências Sociais pela Unicamp, professora da PUC Campinas. E-mail: catiamu@uol.com.br. 
Os estudos sobre mudanças na esfera do trabalho foram marcados, na década de 1990, pela afirmação praticamente generalizada de que essas mudanças eram consequiência do esgotamento do modelo fordista-taylorista de organização dos processos de trabalho e gerenciamento da produção e dedicaram atenção especial às alterações nas formas de organização da produção e do desenvolvimento dos processos de trabalho para avaliar, posteriormente, as conseqüências sobre as relações de trabalho: precarização, intensificação do trabalho e retração da ação sindical.

Ou seja, buscava-se detectar as mudanças na esfera do trabalho pelo acompanhamento do próprio processo da produção e da organização do trabalho, sendo que a sua precarização e intensificação bem como o declínio da mobilização dos trabalhadores, eram entendidos como decorrência direta desse processo. Ấ medida que os avanços tecnológicos alteram o conteúdo, a forma e o ritmo do trabalho, desenvolvem-se novos processos de trabalho, novas formas de gestão, maximização da produtividade e do lucro, em acordo com a lógica de mercado vigente. ${ }^{2}$ Como consequiência, os trabalhadores perdem direitos conquistados ao longo de décadas, devido à flexibilização das leis trabalhistas, e sofrem um processo de intensificação do trabalho, como resultado das mudanças na produção e dos altos índices de desemprego. ${ }^{3}$

Em Rodrigues (2001) foi proposta uma outra perspectiva ao estudo das mudanças na esfera do trabalho. Mesmo considerando as implicações do processo de investimento em tecnologias como fundamentais ao entendimento das alterações profundas que vêm ocorrendo na esfera do trabalho, chamou-se a atenção para a necessidade de observar outras variáveis presentes nesse processo. No caso estudado, a dimensão cultural, pela manipulação de valores e símbolos, foi central ao entendimento do processo de mudanças no Banco do Brasil, o impacto dos acontecimentos sobre a empresa e sobre o quadro funcional, como e porque os fatos ocorreram da forma como ocorreram, porque a mobilização sindical não reverteu o processo e como tudo isso permitiu que a empresa realizasse mudanças substantivas nas relações de trabalho. Dessa perspectiva, problematizava-se estudos pautados em uma visão unilinear sobre as mudanças na esfera do trabalho e considerava-se a dimensão simbólica como uma variável intrínseca aos processos.

${ }^{2}$ Sobre as discussões teóricas a respeito, vide, por exemplo, Coriat (1988, 1994), Freyssenet (1995), Gorz (1991), Harvey (1989), Piore e Sabel (1984), Linhart (1997), Lipietz (1991, 1995). No Brasil, vide, por exemplo, Antunes (1995, 1999), Gitahy (1992, 1994), Hirata (1993), Humphrey (1994) e Mattoso $(1994,1995)$. Como referência de estudos empíricos, vide Kern e Schumann (1989), Linhart et alli (1999) e Morthé (1999).

${ }^{3}$ Vide, entre outros, Antunes (1995, 1999), Babson (1995), Mattoso (1994, 1995), Rifkin (1995). 
É no mesmo sentido que o presente artigo, ao comparar duas experiências ocorridas em empresas de natureza distintas: uma pertencente ao setor financeiro, de capital misto, e uma indústria multinacional de capital privado, permitirá perceber a forma como determinadas categorias de trabalhadores são colocadas em situação de maior risco durante esses processos, os mecanismos simbólicos de exclusão e as conseqüências sobre esse contingente de trabalhadores.

Tudo isto, é claro, aponta para a necessidade de considerar a heterogeneidade da chamada "classe trabalhadora" problematizando noções como identidade e cultura de classe.

Cabe ressaltar que embora estudos elaborados no bojo das mudanças ocorridas na década de 1990 afirmassem a fragmentação dos coletivos de trabalhadores e a acentuação das posturas individualistas, com retração da atuação sindical (Cattani, 1996; Antunes, 1997), bem como uma menor homogeneidade na composição da mão-de-obra manual, pela inserção de minorias étnicas e crescimento do contingente de mulheres (Antunes, 1997; Beyon, 1995; Dedecca, 1996), o que levou alguns autores a enfatizar a necessidade de articular gênero e raça à perspectiva de classe, há que se enfatizar a importância dos estudos feministas, ou sobre "mulheres", desenvolvidos a partir da década de 1970, que, já `aquela época, problematizavam o conceito de classes sociais e sua operacionalização no meio intelectual que tendia a apresentar uma imagem da classe operária relativamente homogênea desconsiderando as relações de gênero como produtoras de diferenças (Hirata e Kergoat, 1994).

Conquanto esse debate tenha se ampliado ao longo da década de 1990 (Brito,1999; Castel, 2000; Hirata, 2002; Antunes, 1999) variáveis como raça, etnia, gênero, ${ }^{4}$ e outras que serão aqui abordadas, não têm sido consideradas em sua devida importância no entendimento da dinâmica dos processos de mudança na esfera do trabalho, principalmente no que se refere às estratégias empreendidas pelas empresas na exclusão de determinadas categorias de trabalhadores, colocando-os em situação mais vulnerável no cotidiano do trabalho e nos momentos de redução de quadros.

No primeiro caso relatado neste artigo a ênfase incide sobre as relações de gênero. Já no segundo caso é contemplado um leque mais amplo de variáveis: gênero, idade, estado de saúde, participação política etc. Os mecanismos de exclu-

${ }^{4}$ Com respeito à consideração das variáveis étnicas e identitárias no estudo das transformações capitalistas contemporâneas, vale destacar o trabalho de Sennet (1999) ao comparar as mudanças ocorridas numa padaria por ele pesquisada 20 anos antes e à qual ele retorna na década de 1990, já totalmente automatizada, com trabalhadores flexíveis, com redução dos níveis de solidariedade antes existentes. 
são são similares, pois em ambos os casos são criadas designações para certas categorias de trabalhadores, excluídos dentro do próprio local de trabalho, dotadas de forte conteúdo simbólico: as "alocadas", no primeiro caso, e os "excedentes", no segundo.

\section{As trabalhadoras denominadas "alocadas" em uma fábrica" localizada no interior do Estado de São Paulo}

Apresento, a seguir, uma das formas de exclusão do trabalho feminino praticada na área produtiva de uma fábrica localizada na região de Campinas, Estado de São Paulo. Durante a minha pesquisa de mestrado (Muniz, 2001) foram relatadas, por parte das trabalhadoras da área produtiva da referida fábrica, insatisfações quanto ao processo seletivo interno de escolha de trabalhadores na área citada. Esse processo vem se dando, desde 1990, pela escolha dos próprios trabalhadores e, segundo vários relatos, privilegiando as relações de amizade com os candidatos ao invés da "competência". A exclusão das operárias nesta área se inicia, de acordo com diversos relatos, com o afastamento de trabalhadoras da rotina de seu trabalho por alguma doença - geralmente por Lesões por Esforço Repetitivo, ${ }^{6}$ causadas principalmente pelo trabalho intensivo e repetitivo nos finais das linhas (embalagens) - por algum acidente ou gravidez. As trabalhadoras nestas condições são afastadas de suas funções, ficando sem grupo, ${ }^{7}$ e passam a realizar tarefas em grupos que estejam sem um dos componentes ou auxiliam os coordenadores no trabalho de escritório, tais como: xerox, preenchimento de formulários, entre outros.

Numa das fábricas estudadas por Cibele Risek e Márcia Paula Leite (1998) havia trabalhadoras denominadas "de reserva" que se encontravam numa situação semelhante à das "alocadas" na fábrica estudada, ou seja, trabalhadoras que a cada dia são escolhidas para abastecer as máquinas e para substituir outras operárias nas eventuais faltas e paradas. Esta denominação é uma classificação elaborada na fábrica em São Paulo, pois na sua filial localizada em Recife não há esta denominação e os trabalhadores e trabalhadoras em situação semelhante são chamados de "ajudantes de produção".

${ }^{5} \mathrm{~A}$ fábrica mencionada foi pesquisada em minha dissertação de mestrado, pertencendo a uma empresa no Brasil ligada a um grupo anglo-holandês. Esta fábrica produz produtos pessoais tais como: desodorantes, shampoos, sabonetes líquidos, cremes hidratantes, cremes dentais.

${ }^{6} \mathrm{Na}$ indústria estudada por Pollert (1996) também é observado que a LER, como na fábrica estudada, é produto do aumento da velocidade e da intensificação do trabalho nas áreas de embalagens das linhas.

${ }^{7} \mathrm{O}$ trabalho produtivo na fábrica estudada é realizado em grupos semi-autônomos, baseados no modelo da fábrica da Volvo na Suécia. Ver definição em Fleury (1985). 
Segundo alguns relatos, dificilmente uma trabalhadora na situação de "alocada" consegue se reintegrar a um grupo novamente devido à maneira como estão sendo realizadas as escolhas dos integrantes desses grupos de trabalho. Contudo, o caso estudado revela um forte sentimento de ambigüidade e invisibilidade nesta situação. Relatou uma das operárias que trabalhava há seis anos em um determinado grupo que quando necessitou de afastamento por um mês, devido a problemas causados pela LER (lesão por esforço repetitivo), embora continuasse a ajudar diariamente na linha, com a parte teórica de um programa que estava sendo implementado na área, os integrantes do seu grupo alegaram que ela estava atrapalhando o andamento do serviço e com base nesse argumento não a aceitaram de volta. A atitude tomada pelo grupo foi a substituição desta operária por um outro trabalhador que, segundo seus comentários, não havia tido ainda nenhum treinamento enquanto ela já havia passado por seis etapas do programa. Na interpretação desta operária, ela foi excluída do grupo por ser mulher. Apesar dos trabalhadores da área terem afirmado que ocorre o mesmo com os homens, quando estes ficam doentes, um dos coordenadores disse que é uma tendência na fábrica a existência de mais mulheres na condição de "alocadas", devido ao próprio processo de escolha dos integrantes dos grupos. Diferentemente de outras empresas, na fábrica pesquisada os trabalhadores e trabalhadoras recebem a mesma qualificação, já que executam as mesmas tarefas mas, como nos mostra o caso citado, muitas vezes as trabalhadoras são impedidas de praticar seu treinamento porque estão fora dos grupos de trabalho, o que impede o desenvolvimento de seu processo de qualificação na empresa.

A justificativa dos operários, sobre o não retorno das "alocadas" aos seus respectivos grupos, é a seguinte:

Aí o que acontece, se vai uma cada dia uma pessoa na linha você precisa ensinar e se for uma linha rápida não dá tempo, e aí no outro dia vai uma outra pessoa diferente, então isso aí atrapalha. Tem grupo que opta por tirar a mulher neste caso, e aí ela vai fazendo um serviço paralelo, faz serviço de coordenador. Geralmente escolhem homens para ficar no lugar.

Outro trabalhador relatou que há uma certa pressão da empresa, confirmado por um dos coordenadores da área, para que se obtenha maior produtividade, sendo este um dos motivos da substituição aos colegas afastados tornar-se permanente. Os trabalhadores são cobrados para que atinjam as metas estabelecidas de produtividade e de qualidade dos produtos e quando o substituto é uma pessoa que tem um bom desempenho optam por que este continue em caráter permante. Esta justificativa, porém, não responde à questão sobre a preferência por substitutos homens. 
As trabalhadoras da manufatura discorreram sobre a condição de "alocada" quando estão em RAP (Recuperação da Atividade Produtiva), ou seja, quando saem de licença por motivo de doença, regressam ao trabalho, mas não voltam a exercer suas antigas funções até se recuperarem totalmente. Realizam outras atividades que não prejudiquem sua recuperação, no entanto, segundo dizem, seus colegas homens acabam interpretando este estado como se elas não quisessem trabalhar e não como se elas não pudessem trabalhar. Uma delas disse que não pretende voltar a esta situação, pois não agüentará novamente passar pela série de humilhações que os trabalhadores da área fizeram-na sofrer. Segundo uma das entrevistadas, estes concluem que uma vez que as "alocadas" em RAP estão na fábrica já estão recuperadas para voltarem ao trabalho. $\mathrm{Na}$ interpretação desta operária, seus colegas só acreditariam que ainda estão em recuperação se aparecessem na fábrica sentadas em cadeiras de rodas, ou coisa parecida. Uma outra relatou que se por acaso elas necessitam atender o telefone é comum ouvir comentários como: Ô telefonista!!! Só atende telefone... Desabafa: Eu não agüento isto. Eles acham que é frescura sua, afirma uma delas.

Um dos coordenadores confirmou esta situação vivida pelas mulheres em RAP: de se sentirem deslocadas e mesmo muito deprimidas quando começam a ouvir os boatos de que o grupo não as quer de volta. Para este entrevistado, os grupos deveriam valorizar os trabalhadores e trabalhadoras que estão em situação de RAP, mas o que acontece é o esquecimento, por parte do grupo, de todo o trabalho desenvolvido por aquela pessoa durante o tempo em que fez parte do grupo. Novamente aparece no relato a questão da invisibilidade destas pessoas para os demais grupos pois estas passam a não existir para os demais trabalhadores.

Tudo é muito semelhante ao que Norbert Elias (2000) afirma em Os estabelecidos e os outsiders, já que, no primeiro caso, os indivíduos,

são mais inseguros, mais incertos acerca de seu valor coletivo, tendem à mais aguda hostilidade na estigmatização de grupos outsiders, a ser implacáveis na luta pelo status quo e contra uma queda ou abolição dos limites entre estabelecidos e outsiders. Normalmente são eles quem mais têm a perder no caso de uma ascensão dos outsiders (Elias, 2000, p. 212).

Há uma declarada estigmatização das trabalhadoras em situação de "alocadas" na fábrica estudada. Os relatos coletados revelam uma hostilidade dos trabalhadores em relação às trabalhadoras e a manutenção da superioridade dos trabalhadores na produção, pelo menos numericamente. ${ }^{8}$ É necessário esclarecer que não há apenas mulheres na condição de RAP, há homens também, entretanto, segundo os relatos, a situação é mais desagradável para as mulheres, pois há uma maior exigên-

${ }^{8}$ Há 682 trabalhadores na área produtiva, dos quais 591 são homens e apenas 91 são mulheres. 
cia de desempenho dessas trabalhadoras por parte dos seus colegas operários, além de serem preteridas no momento do retorno ao seu grupo.

Para uma trabalhadora da área administrativa entrevistada, o RAP deveria ser acompanhado mais de perto pela empresa, porque a maioria das pessoas que estão nestas condições acabam fazendo mais esforço do que deveriam. Esta trabalhadora considera necessário um acompanhamento da área de saúde juntamente com a coordenação, com o intuito de orientar os coordenadores para quais tipos de atividades as pessoas nestas condições podem ser encaminhadas.

A gravidez também é um fator de afastamento das trabalhadoras dos seus respectivos grupos pois é preciso antecipar a sua saída devido ao esforço físico exigido para executá-lo. Para um dos coordenadores, há grupos que querem sua colega de volta ao grupo ao término da licença maternidade enquanto há grupos que querem a substituição ou saída imediata da trabalhadora.

Há um programa desenvolvido pelo setor de Recursos Humanos da empresa, Projeto Novidade, para as gestantes, que tem por objetivo fazer com que estas se sintam tranqüilas durante a gravidez e permaneçam atualizadas com seu trabalho, para que possam voltar a exercer as mesmas funções sem ter perdido contato com seus projetos, podendo participar dos processos de decisão. Este programa já estava sendo realizado na empresa desde 1996, nas áreas de gerência e administração, mas até o término da pesquisa as operárias ainda não estavam usufruindo deste benefício uma vez que tinham sua saída antecipada por causa do tipo de trabalho exercido. A proposta do diretor de $\mathrm{RH}$ para este tipo de problema seria criarem uma alocação em que teriam uma turma de afastados, seja por gravidez ou RAP. Esta proposta, contudo, não surtirá efeito se continuar sendo praticado o mesmo processo de seleção na produção, já que tem excluído as trabalhadoras. Segundo relatos, o que ocorria é que se uma trabalhadora era afastada por RAP ou gravidez (afastamentos mais prolongados) não conseguia retornar ao seu grupo nem inserir-se em qualquer outro, já que seus colegas de trabalho preferiam companheiros de trabalho homens e preferencialmente que fizessem parte do seu círculo de amigos.

Todos os gerentes da manufatura, assim como os coordenadores desta área entrevistados e, ainda, o gerente da fábrica e o diretor de Recursos Humanos, concordam com a existência de falhas no processo de recrutamento interno na área de produção. O diretor de Recursos Humanos considera que chegou o momento de revisarem esta questão, pois isto faz parte do processo. Até o término da pesquisa, na fábrica em São Paulo, em novembro de 2000, nada havia sido posto em prática para reverter esta situação. 
Um dos coordenadores da manufatura ressaltou a dificuldade da convivência em grupo e a falta de preparo dos trabalhadores para essa convivência. Os coordenadores acreditam que estes trabalhadores necessitam de ajuda e é o papel deles, juntamente com os gerentes, fornecer essa ajuda e também orientação. O papel dos coordenadores à época, segundo relato de um deles, não é mais de vigilância e sim um papel mais social, no qual estariam sempre prontos a ouvir os problemas de seus trabalhadores e na medida do possível tentar auxiliá-los na resolução desses problemas. Entretanto, considerava nem sempre isto ser possível, devido ao número elevado de trabalhadores nesta área, além do trabalho burocrático que lhes toma muito tempo. Segundo outro coordenador entrevistado, haverá uma mudança que poderá estar facilitando um maior contato entre eles e seus empregados com o aumento do número de coordenadores, passando de cinco para oito. Anteriormente este contato dos coordenadores com seus empregados era dificultado também pela troca de grupos a cada dois meses, pois justamente quando estes estavam começando a se familiarizar com os trabalhadores e trabalhadoras de um grupo iniciavam a coordenar outro grupo de trabalho, já afeito ao modo específico de trabalho do coordenador anterior. Com a mudança, segundo afirmaram, deverão trabalhar sempre com as mesmas turmas facilitando a aproximação entre eles e seus empregados.

Para o diretor de Recursos Humanos, está faltando investimento por parte da empresa em treinamentos, não só para os operários, mas também para os coordenadores e gerentes. Sua proposta para melhorar a escolha dos integrantes dos grupos seria um programa de formação de operadores, para as pessoas que estivessem numa lista de espera, e, também, para os interessados em participar do programa. Assim, teriam um pré-requisito mínimo. Desta forma, haveria uma pré-seleção, na qual estariam os trabalhadores e trabalhadoras que realizaram o programa, os quais participariam ainda de uma dinâmica em grupo que poderia estar sendo auxiliada por um especialista de fora, deixando a decisão final para os próprios grupos. Nesta proposta, haveria também a verificação das dificuldades que alguns tiveram na dinâmica para ajudá-los numa próxima oportunidade de vaga.

Um dos coordenadores destaca a importância da escolha final permanecer com os grupos, já que muitos dos trabalhadores da área não vêem apenas o conhecimento teórico do candidato mas, também, o desempenho dele na sua respectiva linha. Pode-se concordar que a "autonomia" dos grupos na escolha dos seus companheiros de trabalho deve ser preservada pois é uma forma de exercerem um certo poder na empresa, porém, a exclusão das mulheres é algo muito sério e grave que parece não estar sendo devidamente considerado. Isto pode ser constatado na proposta citada acima, idealizada pelo diretor de Recursos Humanos, que não menciona em nenhum momento este fato ou como pretende solucioná-lo. 
Outro coordenador lembrou que, no início da formação dos grupos, havia atividades realizadas com os trabalhadores, fora da fábrica, como a montagem de quebra-cabeças ou conversas com o coordenador da equipe sobre as expectativas recíprocas (dos coordenadores em relação aos grupos e destes em relação aos coordenadores). Ao longo do processo estas atividades perderam força mas, na sua interpretação, é algo que poderia ser resgatado.

Os comentários citados foram proferidos numa reunião entre coordenadores da produção e a direção de $\mathrm{RH}$, entretanto, mesmo percebendo que a maioria dos trabalhadores da área produtiva não está considerando a competência como critério fundamental na escolha dos integrantes dos grupos de trabalho, a proposta de melhoria não se concentrou neste fator. Houve, deste modo, um desvio do problema e não foi realizada nenhuma proposta, naquela reunião, de solução para a situação em que muitos trabalhadores, e principalmente as trabalhadoras da manufatura, estão vivendo na fábrica em Vinhedo. Ainda parece permanecer nesta fábrica o que Barbosa (1996) denomina de "ideologia da harmonia", na qual o conflito é algo raro e patológico e

que pode ser evitado através das ações gerenciais adequadas, e não como um processo intrínseco à própria vida social. Portanto, todos os esforços são empreendidos para negá-lo de forma explícita. As mais ardorosas discussões são apresentadas como evolução do grupo; o confronto direto de opiniões e de projetos são permanentemente adiados e a intermediação pessoal é a estratégia institucional adotada (Barbosa, 1996, p. 97-78).

O fato dos coordenadores da área e o diretor de Recursos Humanos sequer terem marcado uma nova discussão para o problema reforça o comentário de Barbosa sobre a empresa evitar confrontos diretos e adiar projetos quando estes dizem respeito aos conflitos internos, neste caso entre trabalhadores e trabalhadoras.

As trabalhadoras entrevistadas, em sua maioria, concordam que o processo de escolha praticado anteriormente a 1990, no qual os coordenadores eram os responsáveis pela escolha dos componentes dos grupos, era mais favorável a elas pois sempre havia mulheres neles, sendo que no ano de 2000 havia grupos que não possuíam mulheres entre seus integrantes. É preciso lembrar que as operárias, ao viver a situação de exclusão, não conseguem perceber a relativa "autonomia" proporcionada pela empresa ao conceder aos trabalhadores o direito à escolha final dos integrantes dos grupos. Também não estão vendo esses mecanismos de escolha como capazes de conferir maior poder de decisão aos trabalhadores dentro da empresa. Isto porque os operários estão tendo dificuldades em lidar com essa "autonomia", não que ela seja vista como negativa, consideram-na de certa forma positiva, mas julgam que os mecanismos necessitam ser melhor trabalhados ou até reformulados. 


\section{Os "excedentes" no processo de mudanças no Banco do Brasil $(1995-2000)^{9}$}

Em julho de 1995, no início do governo Fernando Henrique Cardoso, o Banco do Brasil levou a efeito o maior programa de demissões incentivadas até então realizado no Brasil. Este foi considerado um sucesso mundial ${ }^{10} \mathrm{e}$ programas similares disseminaram-se por todo o setor público e estatal, nos anos subseqüentes, tornando-se estratégia de redução de quadros mesmo em empresas do setor privado. Entretanto, o acompanhamento do processo de sua implementação e dos seus desdobramentos mostrou que esse sucesso foi resultado de específicas estratégias de ação pautadas na adoção de medidas unilateriais, excludentes e coercitivas.

Faltando cinco dias para a efetivação das demissões, que ocorreram todas em 31 de julho de 1995, de forma maciça e em todo o Brasil, a empresa iniciou um grande movimento de transferências de funcionários, ${ }^{11}$ como parte do programa de redução de quadros nas agências e os excedentes, em todo o país, foram convidados a buscar colocação em agências onde houvesse vagas e a se transferir para essas localidades no prazo de uma semana.

A criação da categoria excedente, pelo Banco do Brasil, pode ser considerada como um dos mecanismos mais violentos dentro do processo de mudanças ocorrido na empresa. Não apenas por ter se tornado um mecanismo de exclusão de determinadas categorias de funcionários, sobretudo as que se encontravam de alguma forma em situação mais vulnerável no processo de escolha, mas porque a própria categoria excedente assim formada passava a ser alvo dos mais variados tipos de discriminação.

O excedente, tão logo assim categorizado, era excluído do quadro de funcionários da agência. Para eles foi criado um código de localização "virtual" e, dessa forma, mesmo trabalhando na dependência onde então se encontravam, eles passavam a fazer parte do Quadro de Excedentes pertencente à Direção Geral. ${ }^{12} \mathrm{E}$ isto resultava, muitas vezes, em conflitos no local de trabalho.

Sem ter um lugar definido de trabalho, transitando entre setores, sendo ignorado ou marginalizado pelos antigos colegas e chefias, o excedente era um "não funcionário", e era como um morto-vivo que ele prosseguia trabalhando.

${ }^{9}$ Os dados aqui trabalhados fazem parte da tese de doutorado (Rodrigues, 2001), que contou com apoio e recursos da Fundação de Apoio à Pesquisa do Estado de São Paulo (Fapesp).

${ }^{10}$ BB reservado n. 56, Revista Ícaro (nov. 1998) e site da DBM do Brasil.

${ }^{11}$ Embora não se trate de empregados do setor público, os termos funcionário e correlatos serão utilizados por serem categorias êmicas.

${ }^{12} \mathrm{O}$ excedente ficava classificado como: Lotação: 89699 QE QUADRO DE EXCEDENTES DF. 
O excedente não era apenas um excluído na sua unidade de trabalho. Quando ele se transferia, carregava a marca de sua condição; chegava sempre a outra dependência como alguém que foi descartado e que, já de antemão, era considerado um mau funcionário. Havendo a possibilidade de ocorrerem novas mudanças ele sempre estaria na situação mais precária, podendo novamente estar na situação de excedente caso houvesse nova redução de quadros.

Como a estratégia da empresa foi a de centralizar as atividades tecnológicas em Brasília, os centros de processamento de dados $(\mathrm{Cesec})^{13}$ - unidades que abrigavam números elevados de funcionários - foram desativados paulatinamente ao longo dos três anos seguintes, de forma que a cada fechamento de um centro seus funcionários eram postos na condição de excedente e obrigados a procurar uma nova alocação, muitas vezes em um outro Cesec também em perspectivas de extinção.

Na edição de abril de 1997 de O Espelho, jornal dos funcionários do Banco do Brasil, editado pelo Sindicato dos Bancários de São Paulo, há um alerta com respeito à discriminação sofrida pelos funcionários excedentes dos Cesec que estavam sendo desativados naquela Capital. Segundo o jornal, esses funcionários tinham que empreender uma verdadeira "peregrinação" às agências em busca de vagas quando eram submetidos a vários tipos de humilhação, desde ser deixado horas à espera para ser atendido pelo gerente e ao final ser rejeitado devido ao tempo de Banco ou por não atender ao perfil desejado.

Mas não havia excessos de funcionários no Banco do Brasil. Toda a documentação proveniente do material secundário e das entrevistas mostra que em todo o país havia falta de funcionários e excesso de serviços, com a realização rotineira de um número bastante elevado de horas extras não remuneradas (Rodrigues, 2001).

Assim, é mais correto entender esses números de excedentes fixados pelo Banco como uma estratégia para garantir a continuidade dos serviços em todo o país no período posterior ao PDV. Estratégia que consistiu em aumentar a pressão sobre o funcionalismo no intuito de exigir uma adequação total às propostas da empresa, reduzir ainda mais o quadro de funcionários ao longo do tempo e, seguindo sua estratégia de banco de mercado, concentrar os interesses na região Centro-Sul, especialmente a região Sudeste.

${ }^{13}$ Antes da implementação do Programa de Ajustes os Cesec eram em número de 142 e contavam com 25.902 funcionários concursados, de um total de 117.268 existentes no país em fevereiro de 1995. À época existiam também 26.731 estagiários, a maioria em situação irregular (conforme processos existentes na Procuradoria do Trabalho em Brasília). 
O quadro de excedentes em julho de 1995 contava com um total de 5.617 funcionários a serem transferidos. Destes, 1.967 poderiam se deslocar dentro do próprio estado e 3.650 teriam que obter vaga em outro estado da Federação. Mas como o número de vagas disponíveis, 5.228, era menor do que o de excedentes, num primeiro momento 389 funcionários já não encontrariam vagas no pós PDV.

Os estados da região Nordeste foram particularmente atingidos pelo remanejamento de funcionários uma vez que do conjunto de funcionários postos na condição de excedentes e obrigados a se deslocarem para fora do estado, 64,5\% pertenciam àquela região. Isoladamente, Minas Gerais foi o estado mais atingido, com cerca de $30 \%$ do total das transferências para fora do estado. A região Nordeste, mais Minas Gerais, respondeu por $94,5 \%$ do total e aos outros estados corresponderam os 5,5\% restantes das transferências.

Em resumo, a estratégia adotada para a automatização da empresa deu-se via centralização de dados em Brasília. No ano de 1998 o banco construiu um grande Centro Tecnológico com a finalidade de armazenar toda a base de dados da empresa, controlar e monitorar o funcionamento do sistema em todo o país. Com esta opção, o processo de centralização se daria com seguidos movimentos de fusões de Cesec, com a transferência de serviços e funcionários (obviamente que em quantidade cada vez menor) para os Cesec de maior porte. Enquanto os Cesec iam sendo fechados os seus funcionários viam-se obrigados a solicitarem transferência ou aderirem ao Programa de Adequação de Quadros (PAQ), uma versão modificada do PDV, que, em resumo, significava a adesão "voluntária" à demissão incentivada (com benefícios cada vez menores).

E assim, sucessivamente, foi ocorrendo a desativação dos centros e por este motivo pode-se entender que, em 1997, o número de excedentes em todo o país estivesse perto de 8.000 funcionários, número bem mais elevado que em 1995.

As denúncias que chegaram ao Ministério Público do Trabalho no período pós PDV chamam a atenção para o caráter discriminatório do programa de transferências afirmando que o banco não estava observando os princípios constitucionais da impessoalidade e isonomia na confecção das listas de empregados excedentes, elegíveis tanto no PDV como no PTV (Programa de Transferências Voluntárias).

Em outras palavras, tais listas foram elaboradas por critérios subjetivos, não públicos e perversos. E tanto isso é verdade, que o requerido (BB de Londrina, a R Tietê) ao estabelecer o rol de excedentes para transferência - a partir de Londrina - optou, injustificadamente, pelas mulheres grávidas, em licença maternidade, aposentados, empregados em licença saúde e outros em situação idêntica, com o intuito claro de criar condições insustentáveis a esses empregados, provavelmente 
visando a caracterização de uma insubordinação justificadora de uma dispensa com justa causa. ${ }^{14}$ (grifos meus)

Depoimentos apresentados, anexos às denúncias feitas por Sindicatos de vários estados da Federação, indicam o mesmo tipo de ocorrência. De onze depoimentos colhidos pela Procuradoria Regional do Trabalho da $19^{a}$ Região, Maceió (AL), verifica-se que o processo de escolha deu-se sem qualquer tipo de consulta aos funcionários e que dentre os indicados como excedentes havia funcionários cujo cônjuge estava impedido de deslocar-se para outro estado, devido à situação de trabalho - funcionário público municipal ou estadual; dois eram casais de funcionários, um excedente e outro não. Também problemas diversos de ordem familiar além de dois casos referentes a problemas de saúde.

Há o depoimento de outro funcionário relatando que foi informado de sua inclusão na lista dos excedentes quando estava em licença para tratamento de saúde. Os depoentes eram de Alagoas e também justificavam a sua insistência em permanecer naquele estado porque além das dificuldades de ordem familiar e de saúde não teriam condições de se manter financeiramente em estados da região Sudeste.

Esta documentação constante dos processos foi fundamental para a pesquisa uma vez que confirmava com mais exatidão e segurança aquilo que já havia sido constatado em Campinas, São Paulo, durante a realização de pesquisa de campo, em maio de 1996.

Àquela época, o Cesec-Campinas estava recebendo inúmeros funcionários vindos de todo o país, não só porque havia sido alto o índice de adesão naquela dependência como pelo fato de estar absorvendo serviços de outros Cesec localizados na região e que estavam sendo desativados. O número total de funcionários e estagiários, no Cesec Campinas, havia praticamente dobrado e tive a oportunidade de percorrer os salões, repletos de novos funcionários, conversar com vários deles e assim perceber a extensão do drama vivido por muitos desses excedentes.

Foi possível o contato com várias mulheres, categoria particularmente prejudicada no processo, ${ }^{15}$ funcionárias que haviam deixado a família, filhos de todas as

${ }^{14}$ Extraído da denúncia apresentada pelo Sindicato dos Bancários de Londrina e Região (PR), em 15.08.1995 e que faz parte do Anexo XXII do ICP 004/93 da PGT, Brasília (DF).

${ }^{15}$ Enquanto $56 \%$ das mulheres não exercia cargo comissionado, o percentual de homens na mesma situação era de $44 \%$ e o não exercício de comissão para funcionários acima de 12 anos de Banco já colocava o funcionário como elegível, o que mostra a maior vulnerabilidade dessa categoria. A grande maioria das mulheres comissionadas ocupava cargo de caixa $(75,5 \%)$ o que já as colocava em sua maioria como elegíveis no momento do PDV, também era essa uma das comissões que o banco pretendia extinguir com seu projeto de "caixa zero". A rejeição de 
idades, a centenas de quilômetros de Campinas. Uma delas havia regressado da licença-maternidade quando foi colocada como excedente e teve que se transferir para Campinas quando ainda amamentava o filho de poucos meses que, dadas as dificuldades, havia ficado na cidade de origem, distante cerca de mil quilômetros.

Outra funcionária estava instalada em um apartamento praticamente desprovido de móveis, que ela passara a dividir com outras mulheres que enfrentavam a mesma situação. Esta funcionária sofria de obesidade e foi deitada em um colchão colocado sobre o chão, do qual mal podia erguer-se, que me forneceu as informações, dizendo haver sido colocada como excedente por sua condição de saúde e que havia deixado marido e três filhos numa cidade mais ao interior do estado de São Paulo, distante cerca de 8 horas de Campinas. Viajava todos os finais de semana para sua cidade o que fez as despesas financeiras aumentarem demais e por isto já considerava a possibilidade de demitir-se caso não conseguisse reverter a transferência.

Funcionários excedentes que se recusaram a pedir transferência para outras dependências foram alvo de maior pressão e dentre estes 537 foram demitidos sumariamente em abril de 1997.

Em junho de 1996 já haviam ocorrido as primeiras demissões compulsórias, de 57 funcionários ${ }^{16}$ e já nesses casos podia-se notar algumas características recorrentes. Dentre os 57 demitidos havia funcionários que contavam com habitualidade, ${ }^{17}$ ações contra a empresa tramitando, ou já ganhas na justiça, ou tinham garantido a permanência na localidade por concessão de liminar judicial.

Em carta enviada ao Ministério Público do Trabalho, o Sindicato dos Bancários de Juiz de Fora, comunicou a demissão de uma funcionária, em junho de 1996, esclarecendo que: havia Ação Civil Pública contra as transferências compulsórias no Banco, com parecer favorável ao Sindicato e recurso interposto pelo banco. E que no mesmo local de trabalho havia cerca de 30 excedentes embora também 115 estagiários trabalhando de forma ilegal.

A direção da empresa negava essa relação entre a situação do excedente e o ato da demissão, informando que as mesmas foram proporcionais ao número de excedentes em cada estado e que não foram considerados como critérios: a existência de habitualidade, liminar ou qualquer outro parâmetro dessa natureza. ${ }^{18}$

mulheres a fazer horas extras em excesso, devido à situação familiar, colocava-as também em situação de maior risco no momento da indicação de excedentes.

16 Boletim Garef, n. 329, 12.06.96.

17 Refere-se a direito adquirido quanto ao ganho de horas extras feitas por período superior a dois anos.

18 Boletim Garef, n. 329, 12.06.96. 
No entanto, levantamento feito pelas entidades representativas revelou que entre os excedentes demitidos em 1997, em número de 538, havia predominantemente casos de funcionários que estavam nas condições de: a) habitualidade funcionários de 8 horas, b) funcionários com causas trabalhistas contra o Banco e c) funcionários com estabilidade provisória devido a LER, gestantes e dirigentes sindicais. ${ }^{19}$

Esse levantamento também revelava que as demissões não contemplaram apenas os excedentes de 1995, escolhidos no período do PDV. Consta desses levantamentos casos de funcionários demitidos que haviam se tornado excedentes em 1996 quando da desativação da dependência onde trabalhavam.

Os estados mais atingidos nessas demissões compulsórias foram Ceará, Minas Gerais e Bahia, que correspondem àqueles estados que contaram com maior número de excedentes à época do PDV. No geral a região nordeste continuou sendo a mais afetada durante todo o Programa de Ajustes.

Nas duas ocasiões em que houve demissão compulsória de excedentes, as entidades representativas reagiram, ocorreu a interferência do Ministério Público e a solicitação de esclarecimentos ao banco por parte do Congresso Nacional.

As explicações da empresa foram praticamente similares às sempre fornecidas ao Ministério Público do Trabalho, procedendo à contextualização do Programa de Ajustes e, dentro daquela lógica, explicando a necessidade de redução de quadros com demissões.

Os dados constantes da lista de excessos e vagas apresentada pelo Banco ao Ministério Público, em 1996, mostra que havia um total de 1.931 vagas, concentradas sobretudo em São Paulo (1.106), Rio Grande do Sul (215), Distrito Federal (148) e Rio de Janeiro (133).

Ora, como o número de excedentes em todo o país era então de 8.000 funcionários, está claro que o esforço em buscar uma transferência era uma tarefa, dependendo da situação individual, praticamente infrutífera. Refiro-me sobretudo àqueles que tentavam conseguir transferência para localidades próximas ou dentro do mesmo estado. A concorrência às vagas era da ordem de 4 candidatos para 1 vaga.

Além do mais, como o processo de redução dos Cesec se deu com a absorção dos serviços e, portanto, com a necessidade de transferência também de funcioná-

${ }^{19}$ De 171 funcionários demitidos 81 (47\%) estavam nessas situações: 52 por habitualidade ou ação na justiça, 24 por doenças (15 com LER), 2 em situação de gravidez e 3 representantes sindicais. 
rios em número menor de um centro para outro, ocorreu que para muitos excedentes a única opção era transferir-se para um outro Cesec que posteriormente seria fechado. Ou seja, o funcionário teria que enfrentar todo o desgaste da transferência para ver-se, às vezes muito rapidamente, na mesma situação anterior. Como esses excedentes eram sempre os mais novos na dependência aonde chegavam, quando havia necessidade de diminuição do quadro de funcionários da dependência o ex-excedente era o candidato natural a se tornar novamente excedente.

Quando do levantamento de dados em Aracaju (SE), em 1998, conversei com uma funcionária que enfrentava uma situação desse tipo. Vera tinha 04 filhos, o menor excepcional, era enfermeira formada e por isto havia conseguido trabalhar como funcionária cedida à Caixa de Assistência aos Funcionários do Banco do Brasil - Cassi, de Aracaju. Estávamos em 28 de novembro e até o dia 30 daquele mês ela estava obrigada a tomar posse no Cesec Aracaju. Só que este Cesec seria desativado alguns dias depois, em 9 de dezembro, o que significava que ela já chegaria na condição de excedente e teria como opções: transferir-se para o Cesec Salvador - que também estava recebendo funcionários transferidos de todo o interior da Bahia - ou simplesmente pedir a demissão. Vera tinha 17 anos de empresa e um salário líquido mensal de $\mathrm{R} \$ 900,00$. Em Aracaju residia em casa de propriedade dos familiares, livrando-se dos gastos de aluguel, o que lhe possibilitava manter os quatro filhos sozinha, já que o ex-marido - também funcionário do banco e de quem se separara recentemente - havia desaparecido após endividar-se com a empresa, sofrer processo administrativo e deixar inúmeros cheques sem fundos que ela foi obrigada a saldar. Não via possibilidades de transferir-se com quatro filhos para Salvador, com um salário de R $\$ 900,00$ e sem saber até quando existiria o Cesec Salvador. Ao mesmo tempo sentia-se insegura para pedir a demissão.

Como este caso, situações semelhantes foram vividas por centenas de funcionários do Banco do Brasil durante o período 1995 a 1998, casos que eram relatados em encontros casuais com funcionários, ex-funcionários e aposentados, e que circulavam de uma agência a outra e entre as diversas cidades do país.

\section{Considerações Finais}

Mesmo considerando-se as diferenças entre os casos relatados, podemos notar, do ponto de vista simbólico, que as categorias "alocadas" e "excedentes" colocam os indivíduos em situação muito semelhante aos atributos de liminaridade desenvolvidos por Victor Turner (1974), em que 
As entidades liminares não se situam aqui nem lá; estão no meio e entre as posições atribuídas e ordenadas pela lei, pelos costumes, convenções e cerimonial. Seus atributos ambíguos e indeterminados exprimem-se por uma rica variedade de símbolos, naquelas sociedades que ritualizam as transições sociais e culturais. Assim a liminaridade frequientemente é comparada à morte, ao estar no útero, à invisibilidade, à escuridão, à bissexualidade, às regiões selvagens e a um eclipse do sol ou da lua (Turner, 1974, p. 117).

E também nas crenças de pessoas em situação marginal, estudadas por Mary Douglas. Afirma a autora que "estas são pessoas que estão de algum modo excluídas do padrão social, que estão deslocadas. Podem não estar fazendo nada de moralmente errado, mas seu status é indefinível” (Douglas, 1976, p. 118).

Douglas cita como exemplo o feto na sociedade Lele, que tem uma posição ambígua porque não se sabe qual será o seu sexo ou se sobreviverá aos riscos da infância e por isso é tratado como vulnerável ou perigoso e emana esse perigo aos outros. O perigo se encontra também nos estados de transição porque este é indefinível, afirma Douglas. Para que o perigo seja controlado há um ritual que separa a pessoa "do seu velho status, a segrega por um tempo e, então, publicamente declara seu ingresso no novo status" (Douglas, 1976, p. 199-120).

Tanto no caso citado por Turner como em Douglas, ocorrem rituais de transição social e cultural. Na fábrica e no banco pesquisados, as trabalhadoras "alocadas" e os "excedentes" assemelham-se ainda, pelo próprio contexto social em que vivemos, à situação de ex-prisioneiros, como também citado por Douglas, no que diz respeito à crescente dificuldade em encontrar uma recolocação.

Essas situações assemelham-se àquela que Taussig (1983) define como "estar no espaço da morte", fora da realidade cotidiana, suspenso momentaneamente no tempo e espaço, quando pela ausência de caminhos traçados a vida perde a continuidade e nada mais é oferecido senão suposições.

Estar como "alocadas" ou "excedentes" pode ser visto simbolicamente como experimentar a condição da "morte social", num sentido próximo àquele apontado por Lévi-Strauss (1975, p. 193). quando se refere à morte por enfeitiçamento, valendo-se das observações de Cannon (1942) em "Vodoo Death".

O trabalho de Cannon relata casos de adoecimento resultando em morte ocasionados pela exclusão social do indivíduo sobre o qual pesa a marca de enfeitiçamento. Considerado como um condenado, um morto-vivo, o enfeitiçado é excluído de todas as atividades da comunidade, como se morto estivesse realmente. Dessa forma, a morte social pode levar à morte natural pois o indivíduo ao verse banido do convívio social, ao perder os referenciais de identificação com o 
grupo, ao ser isolado e ter sua existência negada, aos poucos pode chegar a adoecer e finalmente morrer, pois, como conclui Lévi-Strauss (1975, p. 194), "a integridade física não resiste à dissolução da personalidade social".

Estas analogias são proveitosas para entender os casos narrados, que têm muita proximidade àqueles narrados por Cannon no estudo de tribos africanas, pois são similares aos mecanismos adotados também por outras empresas e que levaram muitos empregados a situações de desespero, suicídios, doenças, quando não à assinatura do pedido de demissão. ${ }^{20}$

\section{Referências}

ANTUNES, R. Para onde vai o mundo do trabalho? In: ARAÚJO, A. M. C. (Org.). Trabalho, cultura e cidadania. São Paulo: Scritta, 1997.

—. Os sentidos do trabalho. São Paulo: Boitempo, 1999.

BABSON, S. Lean production and labor: empowerment and exploitation. In: BABSON, S. (Ed.). Lean work. Detroit: Wayne University Press, 1995.

BARBOSA, Lívia. Análise cultural: Elida Gibbs. Relatório de análise cultural realizado na fábrica e centro empresarial Elida Gibbs, 1996-1997.

BRITO, Jussara. Saúde, trabalho e modos sexuados de viver. Rio de Janeiro: Fiocruz, 1999.

BEYON, Huw A destruição da classe operária inglesa? Revista Brasileira de Ciências Sociais, v. 10, n. 27, fev. 1995.

CANNON, W. B. Voodoo death. American Anthropologist, v. 44, n. 2, abr.-jun. 1942.

CASTEL, Robert. As armadilhas da exclusão. In Desigualdade e questão social. São Paulo: Educ, 2000.

CATTANI, A. D. Trabalho e autonomia. Petrópolis: Vozes, 1996.

CORIAT, B. Automação programável: novas formas e conceitos de organização da produção. In: SCHMITZ, HUBERT e QUADROS, R. (Orgs.). Automação, competitividade e trabalho: a experiência internacional. São Paulo: Hucitec, 1988.

DEJOURS, Christophe. A loucura do trabalho: estudo de psicopatologia do trabalho. São Paulo: Cortez-Oboré, 1992.

DOUGLAS, Mary. Poderes e perigos. In: Pureza e perigo. São Paulo: Perspectiva, 1976.

ELIAS, Norbert e SCOTSON, John L. Os estabelecidos e os outsiders. Rio de Janeiro: Jorge Zahar, 2000.

ENRIQUEZ, E. Perda do trabalho, perda da identidade. In: Relações de trabalho contemporâneas. Belo Horizonte: PUC-Minas/IRT, 1999.

FLEURY, M. T. L. Cultura organizacional e estratégias de mudanças: recolocando estas questões no cenário brasileiro atual. Revista de Administração, São Paulo, v. 26, n. 2, p. 3-11, abr.-jun. 1991.

${ }^{20}$ A respeito, vide Dejours (1998); Xavier (1998); Enriquez (1999); Penella (2000); Schirato (2000); Rodrigues (2001, 2002, 2003). 
FLEURY, Afonso Carlos Corrêa. Organização do trabalho na indústria: recolocando a questão nos anos 80. In: FLEURY, Maria Tereza e FISCHER, Rosa Maria (Orgs.). Processo e relações de trabalho no Brasil. São Paulo: Atlas, 1985.

FREYSSENET, M. La production reflexive: une alternative à la production de masse et à la production au plus juste? Sociologie duTtravail. Paris: Dunod, n. 3, 1995.

GITAHY, L. Reestruturação produtiva, trabalho e educação. In GITAHY, L. (Org.). Reestructuración produtiva, trabajo y educación en America Latina. Campinas: CIIDCenep/Cinterfor-OIT/ IG-Unicamp e Unesco, 1994.

GITAHY, L. Na direção de um novo paradigma de organização industrial? 1992. mimeo. GORZ, A. Métamorphose du travail. Paris: Galilée, 1991.

HARVEY, D. Condição pós-moderna. São Paulo: Loyola, 1993.

HIRATA, H; KERGOAT, D. A classe operária tem dois sexos. Estudos Feministas. v. 2, primeiro semestre 1994.

HIRATA, H. Nova divisão sexual do trabalho: um olhar voltado para a empresa e a sociedade. São Paulo: Boitempo, 2002. Sobre o modelo japonês. São Paulo: Edusp, 1993.

HUMPRHEY, J. O impacto das técnicas japonesas de administração na indústria brasileira. Novos Estudos - Cebrap, n. 38, mar. 1994.

KERN, H.; SHUMANN, M. El fin de la división del trabajo. Madrid: Ministério del Trabajo y Seguridad Social, 1988.

LÈVI-STRAUSS, C. O feiticeiro e sua magia. In Antropologia estrutural. Rio de Janeiro: Tempo Brasileiro, 1975.

LINHART, D. La modernización de las empresas. Buenos Aires: Associación Trabajo y Sociedad, 1997.

LIPIETZ, A. Audácia. São Paulo: Nobel, 1991.

MATTOSO, J. E. L. O novo e inseguro mundo do trabalho nos países avançados. In $O$ mundo do trabalho. São Paulo: Scritta, 1994.

MORTHÉ, A. Impacto da automação sobre o emprego e as relações de trabalho em empresas de autopeças em Minas Gerais. In: Relações de trabalho contemporâneas. Belo Horizonte: PUC-Minas/IRT, 1999.

MUNIZ, C. R As representações nativas do universo fabril: um estudo etnográfico. (Dissertação de mestrado). Campinas, IFCH-Unicamp, 2001.

. A seleção interna e as exclusões de trabalhadoras e trabalhadores na área produtiva de uma fábrica localizada na região de Campinas. Sociedade em Debate. Pelotas, v. 8, n. 2, set. 2002.

. As construções simbólicas de exclusão em uma fábrica no interior do estado de São Paulo. Humanitas, Campinas, v. 4, n. 2, ago.-dez. 2001.

PENELLA, Isabela. LER: uma jornada de sofrimento no trabalho bancário. Dissertação de mestrado em Sociologia: São Paulo, FFLCH-USP, 2000.

PIORE, M.; SABEL, C. The second industrial divide. New York: Basic Books, 1984.

POLLERT, Anna. 'Team work' on the assembly line. In: ACKERS, P. et al. The new workplace 
and trade unionism. Londres: Routledge, 1996.

RIFIKIN, J. O fim do emprego. São Paulo: Makron, 1995.

RIZEK, Cibele Saliba e LEITE, Márcia de Paula. Dimensões e representações do trabalho fabril feminino. Cadernos Pagu, n. 10, 1998.

RODRIGUES, L.C. Banco do Brasil: crise de uma empresa estatal no contexto de reformulação do Estado brasileiro. (Tese de doutorado). Campinas, Unicamp, 2001.

. O Banco do Brasil e as construções simbólicas sobre a idéia de nação. Mosaico, Vitória, v. 2, n. 1, 1999.

Imagens de vida e morte no processo de reestruturação do Banco do Brasil Anthropológicas, Recife, v. 6, n. 13, Série Imaginário, 2002.

. A política das mudanças no sistema financeiro nacional. Revista de Ciências Sociais, v. 33, n. 1, 2002.

Metáforas de amor e paixão, vida e morte, no processo de mudanças de uma empresa do setor financeiro. VIII Reunião de Antropólogos do Norte e Nordeste (Abanne), São Luiz, jul. 2003.

. Mudanças no Banco do Brasil analisadas como dramas sociais. Seminário Organizações e Sociedade: perspectivas transdisiciplinares. Porto Alegre, PPG Ciências Sociais, PUCRS, 2001. CD-ROM.

. Sobre a adoção de programas de qualificação e profissionalização em situações de mudança. Pro-posições, Unicamp, v. 11, n. 3 (33), nov. 2000.

SCHIRATO, M. A. R. O Feitiço das organizações: sistemas imaginários. São Paulo: Atlas, 2000.

SENNET, Richard. A corrosão do caráter: consequiências pessoais do trabalho no novo capitalismo. Rio de Janeiro: Record, 1999.

TAUSSIG, M. Cultura e terror: espaço da morte na Amazônia. Religião e Sociedade, n. 10, nov. 1983.

TURNER, Victor W. Liminaridade e "Comunitas". In: $O$ processo ritual: estrutura e antiestrutura. Petropólis: Vozes, 1974.

XAVIER, E. P. Réquiem aos bancários mortos no trabalho. Porto Alegre: Sindicato dos Bancários de Porto Alegre/Federação dos Bancários do R.G. do Sul, 1998.

Texto recebido em 31.07.2003 e aprovado em 30.08.2003. 